Chapter 10

\title{
Antimicrobial Effect of Probiotics against Common Pathogens
}

\author{
Sabina Fijan \\ Additional information is available at the end of the chapter \\ http://dx.doi.org/10.5772/63141
}

\begin{abstract}
The antimicrobial or antagonistic activity of probiotics is an important property that includes the production of antimicrobial compounds, competitive exclusion of pathogens, enhancement of the intestinal barrier function and others. There are many methods to ascertain probiotic properties, including various in vitro and in vivo methods. The in vivo methods include various modifications of the spot-on lawn assay, agar well diffusion assay (AWDA), co-culturing methods, usage of cell lines and others. In many cases in vitro antagonist activity is observed, but in real settings it is not observed. The in vivo methods mainly used are animal models; however, their use is being restricted according to the European legislation OJ L136. The justification of animal models is also questionable as the results of studies on animals do not predict the same results for humans. The use of replacement alternative methods, for example incorporating human cells and tissues, avoids such confounding variables. Most important studies are doubleblinded randomized clinical trials; however, these studies are difficult to perform as it is not easy to achieve uniform conditions. There is a clear need for more elaborate assays that would better represent the complex interactions between the probiotics and the final host. This complex situation is a challenge for scientists.
\end{abstract}

Keywords: antimicrobial effect, in vitro methods, in vivo methods, pathogens, probiotics

\section{Introduction}

Throughout the history of microbiology, most human studies have been focused on the diseasecausing organisms found on or in people; whilst fewer studies have examined the benefits of the resident bacteria. However, we are surrounded by beneficial microorganisms that live in or 
on the human body. The intestinal microbiota is very well adapted, exceptionally stable and very specific for each individual. In normal conditions of stable functioning of the digestive system, neutral and beneficial microorganisms dominate. It is estimated that there are 100 trillion microorganisms in the intestine of a human adult and this is 10 times larger than the number of cells in the human body [1,2]. However, the balance of the intestinal microbiota is negatively influenced by modern lifestyle, leading to increased numbers of pathogenic microorganisms that disrupt microbial balance and cause a reverse from beneficial to harmful functioning. In such cases, the external support with probiotics is very welcome and supported by several scientific studies [3].

According to the Food and Agriculture Organisation of the United Nations (FAO) and the World Health Organisation (WHO), probiotics are defined as live microorganisms, which when administered in adequate amounts confer a health benefit on the host $[4,5]$. The most common probiotic bacteria are certain strains from the genera Lactobacillus (i.e., L. rhamnosus, L. acidophilus, L. plantarum, L. casei, L. delbrueckii subsp. Bulgaricus, etc.) and Bifidobacterium (i.e., B. infantis, B. animalis subsp. lactis, B. longum, etc.). Other probiotic bacteria include Pediococcus acidilactici, Lactococcus lactis subsp. lactis, Leuconostoc mesenteroides, Bacillus subtilis, Enterococcus faecium, Streptococcus thermophilus, Escherichia coli Nissle 1917, etc. Certain yeasts such as Saccharomyces boulardii are also probiotics $[6,7]$.

Probiotics together with other beneficial microbes are commensals of the gut and differ from pathogenic bacteria in the terms of their actions on immune cells in the gut as they do not stimulate the proliferation of mononuclear cells or trigger an inflammatory action [8]. Regardless of whether the probiotics are used for human or animal consumption, there are several characteristics that a probiotic must achieve. Some of the important characteristics of probiotics include the following: a probiotic must be generally required as safe (GRAS); a probiotic should exhibit bile and acid tolerance in order to survive the path from the oral cavity to the small intestine where it lives, multiplies and excretes beneficial nutrients and molecules; a probiotic should have the ability to adhere to mucus and/or epithelial cells, and/or other surfaces; a probiotic should be susceptible to antibiotics; a probiotic should exhibit antimicrobial activity against pathogens $[3,5,9,10]$. Although it is accepted that probiotics must be of human origin $[4,5]$, many authors have found that some strains that are not normally isolated from human have shown to be effective [11,12], which negates this requirement. As noted above, one of the important attributes of probiotics is their antimicrobial effect against pathogens by maintaining the homeostasis of the intestinal flora. Assessing the antimicrobial effect of various probiotics against pathogenic microorganisms is the guiding concept of this chapter. This chapter reviews the principles and results from various authors of different methods for determining the antimicrobial or antagonistic effect of probiotics against potential pathogens.

\section{Antimicrobial or antagonistic properties of probiotics}

In literature both the terms "antimicrobial" and "antagonistic" are found to determine the ability of one species to inhibit the growth of another species. According to the online Encyclopaedia Britannica, "antagonism" refers to an "association between organisms in which one 
benefits at the expense of the other,." However, this encyclopaedia does not include the adverb "antimicrobial." On the other hand, it contains "antimicrobial agent" that refers to "a large variety of chemical compounds that are used to destroy microorganisms or to prevent their development.." The online Merriam Webster dictionary defines "antimicrobial" as "destroying or inhibiting the growth of microorganisms and especially pathogenic microorganisms" and "antagonistic" as "showing dislike or opposition: showing antagonism."

This antimicrobial/antagonistic ability is especially important for probiotics as one of the functional beneficial requirements of probiotics is a broad antimicrobial spectrum as well as antagonism against pathogenic bacteria with strong antimicrobial activity. The antagonistic activity of one microorganism against another can be caused by competitive exclusion, immune modulation, stimulation of host defence systems, production of organic acids or hydrogen peroxide that lower $\mathrm{pH}$, production of antimicrobials such as bacteriocins, antioxidants, production of signalling molecules that trigger changes in gene expression [13-15]. Antimicrobial substances produced by beneficial microorganisms are known to include lactic acid, acetic acid, formic acid, phenyllactic acid, benzoic acid as well as other organic acids, short chain fatty acids, hydrogen peroxide, carbon dioxide, acetaldehyde, acetoin, diacetyl, bacteriocins and bacteriocins-like inhibitory substances and others [10, 16, 17]. The most common bacteriocins include lacticin, lactocin, pediocin, pisciolin, enterocin, reuterin, plantaricin, enterolysin and nisin $[18,19]$.

\section{Methods}

\subsection{Methods of literature research}

A literature overview of three databases was conducted using the two following keywords: "probiotic" and "antimicrobial" between the years 1980 and 2016. The search yielded 2882, 1017, and 6200 publications in PubMed, Web of Science, and Science Direct databases, respectively (Figure 1).

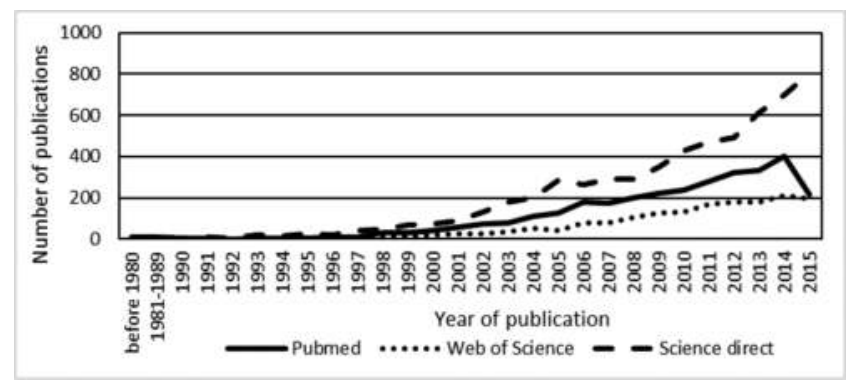

Figure 1. Results of the publications in PubMed, Web of Science and Science Direct databases using keywords: "probiotic" and "antimicrobial" between the years 1980 and 2015. 
All three databases showed great increase in the number of publications in the past 10 years. The highest results were obtained via Science Direct due to the fact that this database includes various journals and books from the area of food and dairy sciences, the area of probiotics for animals as well as the area of human probiotics. PubMed on the other hand contains only research of probiotics for humans. Also, the programs for keyword searching for each chosen database seem to differ among each other thus yielding very different numbers of publications in journals, chapters and conference proceedings. The research on the methods for determining the antimicrobial effect of strain-specific probiotics was conducted by adding an additional keyword aside "probiotic." This keyword described the various investigated methods for determining the antimicrobial/antagonistic activity of probiotics (i.e., spot-on lawn, agar spot, agar well diffusion, paper disc, co-culturing, in vivo). Of course, it was not possible to screen every single article therefore only a selection of the most recent or relevant were used.

\subsection{In vitro methods for determining the antimicrobial/antagonistic effect of probiotics against other microorganisms}

\subsubsection{Spot-on lawn antimicrobial assay/agar spot antimicrobial assay}

The spot-on lawn antimicrobial assay has been described by several authors. Several modifications of the method have been made. Also various other expressions are used such as agar spot assay, critical dilution assay and deferred antagonism assay [10, 16, 20-22].

One of the simplest published principles of the spot-on lawn antimicrobial assay (Figure 2a) consists of the following steps: different nutrients, selective or differential media, are prepared and various chosen indicator microorganisms or pathogens at different initial concentrations are either inoculated in a confluent manner after hardening of agar or are mixed with the agar in liquid state and poured into the plate. Different dilutions of aliquots of the investigated probiotic or cell-free supernatant with bacteriocins are then spotted onto the media already inoculated with chosen indicator microorganisms [20, 23, 24].

After incubation, the antimicrobial activity is expressed either as inhibition zone or as arbitrary units $(\mathrm{AU} / \mathrm{mL})$. The zone of inhibition is noted either as the diameter or the area of the inhibition zone. The critical dilution is noted as the last dilution that produces a zone of inhibition larger than $6 \mathrm{~mm}$. Arbitrary units are defined as the reciprocal of the highest dilution at which the growth of the indicator microorganism or pathogen is inhibited and are calculated as $(1000 / a) \times D$ in $\mathrm{AU} / \mathrm{mL}$, where $a$ is the aliquot of cell-free supernatant added to well in $\mu \mathrm{L}$ and $D$ is the dilution factor $[22,24]$.

A modification is the agar spot antimicrobial assay (Figure 2b) and consists of the following steps: MRS agar or other specified agar is prepared and the probiotic bacteria or test cultures (few $\mu \mathrm{L}$ ) are spotted on. These agars are then incubated to develop spots. Next, the indicator bacteria (pathogenic species, spoilage species and other probiotic species) are mixed into specific soft agar $(0.7 \%)$ and poured over a plate. The plates are then incubated aerobically or anaerobically and the inhibition zones are read. A clear zone of more than $1 \mathrm{~mm}$ around the spot is considered as positive [25]. A third modification is the spot-on lawn antimicrobial assay with wells (Figure 2c), which consists of the following steps: chosen nutrients, selective or 
differential media, are prepared. Wells $(6 \mathrm{~mL}, 7 \mathrm{~mm}$ or other dimensions) are bored in each plate and the bottom of the wells is sealed with agar. Aliquots of active cultures at different dilutions are pipetted into the wells. The plates are left at room temperature to allow migration and settling of the test cultures. The samples are then incubated for $3 \mathrm{~h}$ at $37^{\circ} \mathrm{C}$ and the plates are then overlaid with agar seeded with indicator pathogenic microorganisms (or other indicator organisms) and incubated at suitable incubation conditions. After incubation, the antimicrobial activity is expressed either as inhibition zone or as arbitrary units (AU/mL) [16].

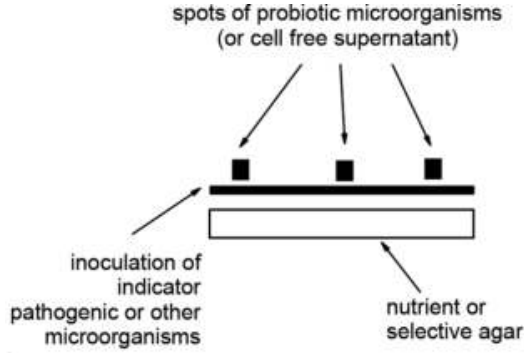

a) Simple spot-on lawn assay

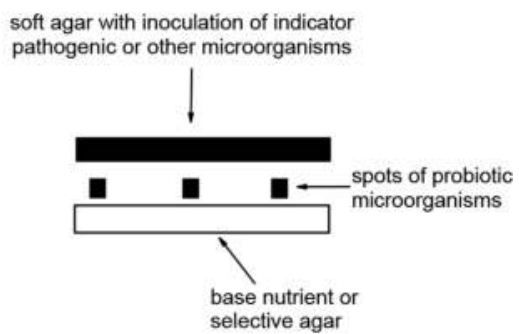

b) agar spot assay
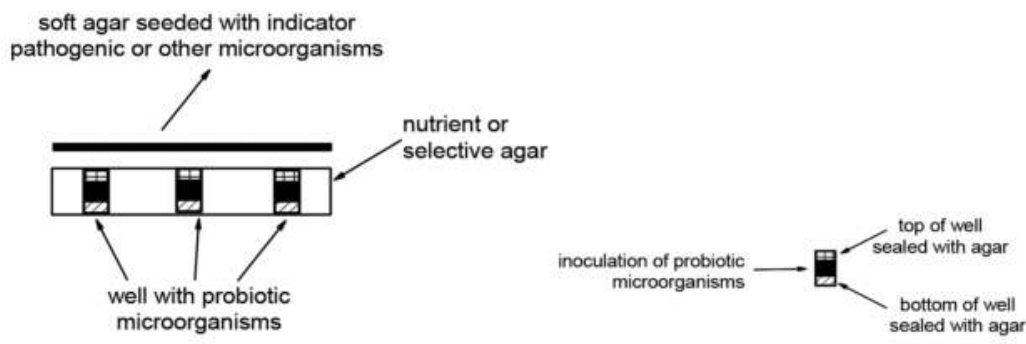

c) Spot-on lawn assay with wells

Figure 2. Schemes of different versions of spot-on lawn/agar spot assays: (a) simple spot-on lawn assay, (b) agar spot assay and (c) spot-on lawn assay with wells.

The fourth modification is the cross streak assay [26] where each probiotic strain is streaked in three parallel lines onto agar using a 1-mL loop. Once these lines have dried, test pathogenic strains are streaked perpendicular to these initial strains in the same fashion, giving three possible zones of inhibition for each combination of strains. It was assumed that when there is inhibition, it is caused by the tester probiotic strain hindering the growth of the secondstreaked (indicator) strain.

\subsubsection{Agar well diffusion assay/paper disc assay}

The agar well diffusion assay (AWDA) (Figure 3a) is used for determining the antagonistic effects of cell-free supernatants. The general principle of agar well diffusion assay consists of 
the following steps: different nutrients, selective or differential media, are prepared. The plates are inoculated with the chosen indicator microorganism. The $6-\mathrm{mm}$ or $7-\mathrm{mm}$ wells are bored in each plate. Aliquots of different dilutions of cell-free supernatants are pipetted into the wells. After incubation, the antimicrobial activity is expressed either as inhibition zone or as arbitrary units $(\mathrm{AU} / \mathrm{mL})[20,22]$. The paper disc assay (Figure $3 \mathbf{b})$ is a modification where instead of making wells, discs measuring $6 \mathrm{~mm}$ are absorbed with aliquots of cell-free supernatant and placed on the agar inoculated with indicator strains. After incubation, the inhibition zone is evaluated based on the clear zone around the paper disc [23].

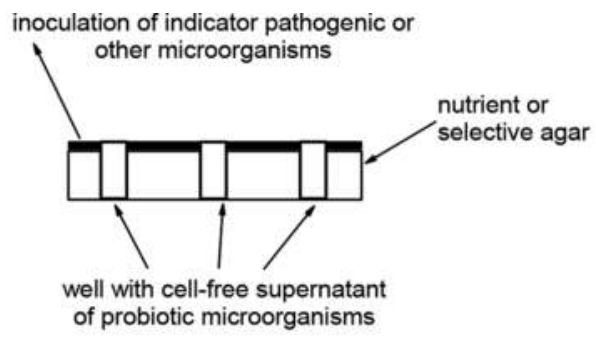

a) Agar well diffusion assay

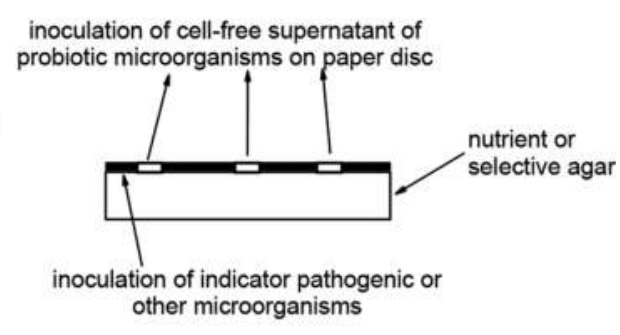

b) Paper disc assay

Figure 3. Scheme of the agar well diffusion assay and paper disc assay: (a) agar well diffusion assay and (b) paper disc assay.

\subsubsection{Co-culturing assays for determining the antimicrobial activity}

Determining the antimicrobial activity of probiotics against common pathogens is also possible with the co-culturing assay. This method includes the following steps: preparation of incubation media (i.e., nutrient broth, reconstituted skim milk, sterilized milk, yogurt, whey, etc.). Aliquots of pathogenic and probiotics microorganisms are inoculated into the incubation media. The samples are mixed well and incubated. After incubation, the population of pathogenic bacteria are counted on appropriate agars. Values are usually expressed as log cfu/ $\mathrm{mL}[14-16,27,28]$.

The microtitre plate assay is a version of the co-culturing assay that includes the following steps: cell-free supernatant of active probiotic or other investigated microorganism is prepared and divided into several parts that undergo different conditions (i.e., $\mathrm{NaOH}$ added to neutralize $\mathrm{pH}$, left acidic, heated, etc.). Pathogenic microorganisms are cultured and added to appropriate broth. The microtitre plate is used to prepare mixes of probiotics/cell-free supernatants and pathogenic microorganisms and incubated at suitable incubation conditions. Before and after incubation, the optical density at $620 \mathrm{~nm}$ is measured and the suppressive activity is calculated as a percentage of inhibition of pathogen growth [15].

Another important type of co-culturing assay is using cell lines. As several important mechanisms underlying the beneficial effects of probiotics include the effects of probiotic properties on specific tissues, particularly on the intestine, the evaluation of probiotic effects on human 
intestinal cell lines in vitro is meaningful as these cells mimic the systemic environment of an organism and are used as a biological matrix alternative to in vivo tests. In fact, in vitro evidence is particularly important considering that the EU directives tend to discourage in vivo experiments on animals [29]. Several different cell lines have been used, such as HT-29 cell line from human colon [29], IPEC-J2 porcine neonatal jejunal cell line [30], Vero African green monkey kidney epithelial cell line [31], Caco-2 colon adenocarcinoma cell line [32], HIEC-6 normal epithelial small intestine cell line [33], BALB/c3T3 murine embryonal fibroblast cell line [29] and many others. Cells are routinely grown in Dubelco's modified Eagles' medium (DMEM), McCoy's 5a medium or other medium and seeded in well plates or microtitre plates that are incubated at $37^{\circ} \mathrm{C}$ for $24 \mathrm{~h}$ in $1 \mathrm{~mL}$ medium in $5 \% \mathrm{CO}_{2}$. Probiotic and pathogenic microorganisms are then added and the cell viability is determined after incubation.

\subsection{In vivo methods for determining the antimicrobial/antagonistic effect of probiotics against other microorganisms}

For in vivo testing, randomized double blind, placebo-controlled human trials should be undertaken to establish the efficacy of the probiotic product. The consultation recognized that there is a need for human studies in which adequate numbers of subjects are enrolled to achieve statistical significance. In order to ascertain that a given probiotic can prevent or treat a specific pathogen infection, a clinical study must be designed to verify exposure to the said pathogen (preventive study) or that the infecting microorganism is that specific pathogen (treatment study). If the goal is to apply probiotics in general to prevent or treat a number of infectious gastroenteritis or urogenital conditions, the study design must define the clinical presentation, symptoms and signs of infection, and include appropriate controls [4].

However, many scientists have reverted to in vivo animal studies. The animal models do not necessarily provide scientifically appropriate and relevant results for human, due to obvious species-specific differences in anatomy, biochemistry, physiology, pharmacokinetics and toxic responses. Especially, in medicine and pharmacy, the "safety testing" on animals led to thousands of deaths worldwide due to the evidence that animal tests are not only worthless, but they are also dangerously unpredictable. The use of replacement alternative methods, especially incorporating human cells and tissues, avoids such confounding variables [32].

The European legislation OJ L136 of 08.06.2000 includes the 3Rs regulation that results in important reduction of studies on animal models and consists of the following. Reduction: using alternative methods for obtaining comparable levels of information from the use of fewer animals in scientific procedure or for obtaining more information from the same number of animals. Refinement: using alternatives methods that alleviate or minimise potential pain, suffering and distress, and which enhance animal wellbeing. Replacement: using alternative methods that permit a given purpose to be achieved without conducting experiments or other scientific procedures on animals [32].

The in vivo animal model antimicrobial study is described as follows: briefly, all animal models include at least two groups under controlled settings. One group receives chosen probiotic and pathogen (treated infected group) and the other receives only the pathogen (untreated infected group). The observed difference includes the exanimation of faeces as well as the examination 
of different cells after scarifying the animals (spleens, lymph nodes, blood, liver, colon, cecum, etc.). Animals used in these studies include mice, rats, chicks, rabbits, pigs, Fish and even worms [30, 34-37]. Work is done under accordance with the guidelines of the European convention for the protection of vertebrate animals used for experimental and other scientific purposes (Directive 86/609/EEC).

\section{Recent results of in vitro antimicrobial/antagonistic assays for various probiotic strains}

The following section contains results of the antimicrobial/antagonistic assays for various probiotic strains or strains with probiotic-like properties against various potential pathogens, spoilage microorganisms, or other probiotic microorganisms. The results reported using different assays (spot-on lawn/agar spot, agar well diffusion/paper disc, co-culturing, microtitre plate and cell line assays) are published by various authors stated in the text and some of the individual procedures are briefly explained.

\subsection{Recent results of selected spot-on lawn/agar spot antimicrobial assays}

The antimicrobial activity of Lactobacillus plantarum EM against seven potential pathogens using the spot-on-lawn assay was conducted by Choi and Chang [10]. The following nutrient and selective media were used: Luria-Bertani agar for E. coli O157:H7 ATCC 43895, P. aeruginosa ATCC 27853, S. enterica serovar Typhi ATCC 19430, nutrient agar supplemented with 2\% $\mathrm{NaCl}$ for $V$. parahaemolyticus ATCC 17802 and tryptic soy agar for B. cereus KCTC 3624, M. luteus ATCC 15307 and S. aureus ATCC 29123. All potential pathogenic bacteria had an initial inoculum of $6 \log \mathrm{cfu} / \mathrm{mL}$. An aliquot of $10 \mu \mathrm{L}$ of L. plantarum EM was spotted onto each plate. The plates were incubated aerobically at $37^{\circ} \mathrm{C}$. After incubation the arbitrary units $(\mathrm{AU} / \mathrm{mL})$ were determined. L. plantarum EM exhibited strong antimicrobial activity against the seven chosen potential pathogenic bacteria. The strongest activity was noted against V. parahaemolyticus, ATCC 17802 (25600 units) and the weakest activity was noted for S. aureus, ATCC 29123 (200 units). As one of the most important requirements of probiotics is a broad antimicrobial spectrum, the authors found that L. plantarum EM fulfilled the beneficial requirements of probiotics [10].

In another research [24], screening for bacteriocins using the spot-on lawn method was used. One hundred and fifty lactic acid bacteria were isolated from samples of traditional fermented Vietnamese pork. The isolate named L. plantarum KL-1 was found to produce bacteriocins, effective against various Gram-positive and Gram-negative bacteria. The test was conducted by preparing two layers of soft agar $(0.8 \%$ agar). The first layers were poured into the plate; then the top layer, which included $5 \mathrm{~mL}$ of soft agar together with $10 \mu \mathrm{L}$ (about $10^{7} \mathrm{cfu} / \mathrm{mL}$ ) of freshly grown test bacterial strains, was added. The Gram-positive strains included S. aureus TISTR 118, E. faecalis JCM 5803, E. faecalis TISTR 888, L. lactis subsp. cremoris TISTR1344, L. mesenteroides JCM 6124, L. mesenteroides TISTR 942, L. sakei subsp. sakei JCM 1157, L. sakei TISTR 890, L. plantarum ATCC 14917, L. inoccua ATCC 33090, Streptococcus sp. TISTR 1030, B. coagu- 
lans JCM 2257, B. coagulans TISTR 1447 and B. campeatris NBRC 11547. The Gram-negative test strains included P. fluorescens TISTR 358, P. fluorescens JCM 5963 and A. hydrophila TISTR 1321. Bacteriocin activity was tested by spotting $10 \mu \mathrm{L}$ of previously prepared cell-free supernatant (in different dilutions) of the isolate L. plantarum KL-1. The inhibition zone was observed after overnight incubation at the proper temperature for each indicator microorganisms and the spectrum was expressed at arbitrary units (AU) [22]. The results show that the antimicrobial activity of the bacteriocin was strain specific. The bacteriocin was most effective against both strains of L. sakei. The bacteriocin was less effective against certain Gram-positive bacteria (both strains of E. faecalis, L. plantarum and both strains of L. mesenteroides subsp. mesenteroides). However, it was not effective against $S$. aureus, both strains of B. coagulans and any of the chosen Gram-negative bacteria.

Tharmaraj and Shah [16] used the spot-on-lawn technique with wells to test the inhibition of chosen pathogenic bacteria (E. coli, S. typhimurium, S. aureus and B. cereus) and spoilage bacteria (B. stearothermophilus and P. aeruginosa) by one strain of L. casei (Shirota YLC); two strains of L. paracasei subsp. paracasei (LCS1, LC01), L. acidophilus (LA5, LAC1) and B. animalis (BB12, BLC1); three strains of $P$. freudenreichii subsp. shermanii (P, PS1, PB10360) and four strains of L. rhamnosus (LC705, LBA, LGG, LR1524). MRS agar was used for lactobacilli (L. acidophilus, L. casei, L. paracasei subsp. paracasei and L. rhamnosus), MRS agar + L-cysteine (0.05\%) for B. animalis, NaLa agar for $P$. freudenreichii subsp. shermanii and nutrient agar was used for pathogenic bacteria. Suitable agar $(25 \mathrm{~mL})$ was poured into the plates and wells were cut with a sterile metal borer. The bottom of the wells was sealed with $0.8 \%$ agar. Active culture $(50 \mu \mathrm{L})$ of producing probiotics was then filled into the wells and left at room temperature for $2 \mathrm{~h}$, followed by incubating at $37^{\circ} \mathrm{C}$ for $3 \mathrm{~h}$. The remaining depth of the well was sealed with $1 \%$ agar. Finally, the spotted plates were overlaid with $10 \mathrm{~mL}$ of $0.8 \%$ agar seeded with about $10^{7} \mathrm{cfu} / \mathrm{mL}$ of pathogenic bacteria. The plates were incubated anaerobically for $72 \mathrm{~h}$ at $37^{\circ} \mathrm{C}$ for all chosen pathogenic and spoilage bacteria. Both chosen spoilage bacteria were additionally incubated aerobically for $24 \mathrm{~h}$ at $37^{\circ} \mathrm{C}$. On average, among all the probiotic and spoilage bacterial interactions, the spore formers were inhibited by the probiotic microorganisms to a greater extent (average zone of inhibition, $19 \mathrm{~mm}$ ) than the non-spore formers (average zone of inhibition, $14 \mathrm{~mm}$ ). Also, the Gram-positive bacteria (average zone of inhibition, $18 \mathrm{~mm}$ ) were inhibited more than the Gram-negative bacteria (average zone of inhibition, $14 \mathrm{~mm}$ ). Strains of $P$. freudenreichii subsp. shermanii did not show notable inhibitory effect.

Soomro et al. [23] also used the spot-on lawn method to determine antimicrobial activity of various Lactobacillus species. They found that L. acidophilus J1 showed an inhibitory effect against $E$. coli. The plates were prepared by inoculating $100 \mu \mathrm{L}$ of indicator strain E. coli grown in broth with $3.5 \mathrm{~mL}$ soft MRS agar and were overlaid over MRS agar. The plates were incubated for $2 \mathrm{~h}$ at $37^{\circ} \mathrm{C}$ after which $30 \mu \mathrm{L}$ of cell-free supernatant of L. acidophilus J1 was spotted onto the overlaid surface. The $\mathrm{pH}$ of the cell-free supernatant was adjusted to 5.5 to eliminate the effect of organic acids and hydrogen peroxide. The plates were incubated at $37^{\circ} \mathrm{C}$ for $18 \mathrm{~h}$ and were subsequently examined for inhibition zones. It was found that the inhibitory effect against $E$. coli was due to the production of a bacteriocin. 


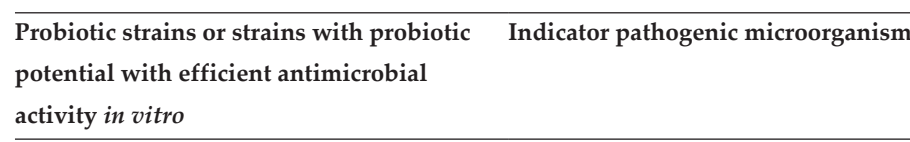

Lb:L. acidophilus La-5, Bb: B. longum ATCC G+:S. aureus, L. monocytogenes;G-:E. coli O157:H7

Lb:L. acidophilus JN188382, L. fermentum

G+:E. faecium ATCC 51558, S. epidermidis ATCC 12228, P. acnes [42] JN188383, L. fermentum JN188384, L. buchneri ATCC 6919, L. monocytogenes, S. aureus S244; G-: E. coli ATCC JN188385, L. buchneri JN188386, L. buchneri 29181, K. pneumoniae K36, E. cloacae, S. sonnei ATCC 25931, H. JN188387, L. casei JN188388, L. casei JN188389, pylori ATCC 43579, V. parahaemolyticus, fng: C. albicans ATCC L. casei JN188390 44831

Oth:E. faecium CV1, LPP29, W. cibaria P71, L. G-:T. maritimum NCIMB2154, LL01.8.3.8, V. splendidus

mesenteroides subsp. cremoris SMM69, $P$.

pentosaceus SMM73, TPP3

Lb:L. plantarum P6

Oth:E. faecalis AP-216, E. faecalis AP 45

Oth:B. subtilis DCU, B. pumilus BP, B. cereus HL7

Lb: LAB 18, LAB 48 G-:S. enterica serovar Enteritidis phage type 13A, E. coli O157:H7, C. jejuni

Lb:L. plantarum CK06, CK19, B01, B07, K09, K10, K21, LM11, ZS07, ZS11 and ZS15

$\mathrm{G}+:$ S. aureus SSV25, S. epidermidis SSV30, S. lentus CCM 3472, E. faecalis V583, L. monocytogenes CCM 4699, G-: A. calcoaceticus CCM 4503; S. paucimobilis CCM 3293; S. enterica subsp. enterica TA100 CCM 3812

Lb:L. fermentum PXN 44, L. plantarum PXN 47 G+:E. faecalis NCTC 00775; G-: E. coli NCTC 9001

Lb:L. paraplantarum FT259

G+:L. monocytogenes IAL 633, L. innocua ATCC 3309

Where probiotics are divided as follows: lb: lactobacilli; bb: Bifidobacterium; oth: other; and pathogens are divided as follows: G+: Gram positive; G-: Gram negative; fng: fungi.

Table 1. A selection of assays published since 2013 of successful antimicrobial activity of chosen probiotics using the spot-on lawn/agar spot assay on chosen pathogenic microorganisms. 
Assays published since 2013 of antimicrobial activity of chosen probiotics using the spot-on lawn/agar spot assay on chosen pathogenic microorganisms are noted in Table 1.

As noted in Table 1, the most common investigated probiotic strains or strains with probiotic potential were from the genus Lactobacillus (L. plantarum, L. acidophilus, L casei and L. fermentum). Several studies included probiotic strains of the genus Bacillus. The most common pathogens included in the assays were S. aureus, L. monocytogenes, E. coli, Vibrio spp. and Salmonella spp. One study examined the antimycotic properties of probiotics against various strains of the genus Aspergillus. Different strains of E. faecium were on the one hand used as probiotics and on the other hand used as potential pathogen, thus proving the dualistic nature of this species.

\subsection{Recent results of selected agar well diffusion assays/paper disc methods}

The agar well diffusion assay was conducted in the research by Ali et al. [51], where 14 isolates with probiotic potential were screened for antimicrobial activity against E. coli and S. aureus. The probiotic isolates were identified as two Lactobacillus spp. (S2a3 and S4b1), eleven Bifidobacterium spp. (FCb1, Kb2, LZa7, LZb8, RC1b8, RC2b4, RC4a3, RC4b2, SCa4, SCb2 and Y2a5) and one Streptococcus spp. (RC2b3). A volume of $100 \mu \mathrm{L}$ of cell-free supernatant of isolates with probiotic potential was filled in $7-\mathrm{mm}$ wells cut in nutrient agar previously inoculated with E. coli or S. aureus. The diameter of inhibition zone was measured after $48 \mathrm{~h}$ of incubation. The supernatant obtained from all 14 isolates exhibited varying degrees of inhibitory activity against $S$. aureus and E. coli. The isolates LZb8, S4b1 and RC4a3 exhibited the superior antibacterial activity with inhibition zones ranged $8.3-8.4 \mathrm{~mm}$. The least activity was recorded for the isolates SCa4 and RC4b2 (inhibition zone ranged 2.3-2.5 mm), whereas the isolates $\mathrm{Kb} 2, \mathrm{LZa} 7, \mathrm{RC} 2 \mathrm{~b} 4, \mathrm{RC} 2 \mathrm{~b} 3, \mathrm{SCb} 2$ and $\mathrm{Y} 2 \mathrm{a} 5$ (inhibition zone ranged 3.5-4.8 mm) were moderately active against $S$. aureus. It is worth mentioning that the inhibitory activity of the tested isolates supernatants was slightly less against E. coli as compared to that obtained against $S$. aureus, indicating that $E$. coli could be less sensitive.

In the previously mentioned research by Soomro et al. [23], the paper disc method was also used. Sterile filter discs measuring 6-mm diameter with an absorbed aliquot of $20 \mu \mathrm{L}$ of cellfree supernatant of L. acidophilus J1 were placed on MRS and nutrient agar plates containing the target strain E. coli. After incubation at $37^{\circ} \mathrm{C}$, the inhibitory activity was evaluated. It was found that the paper disc assay yielded an inhibition zone of $10 \mathrm{~mm}$ and was more appropriate compared to the spot-on lawn assay.

Assays published since 2013 of antimicrobial activity of chosen probiotics using the agar well diffusion assay or the paper disc assay on chosen pathogenic microorganisms are noted in Table 2. The results show that the agar well diffusion assay or the paper disc assay is the most common method used for determining the antimicrobial or antagonistic effect. The most common investigated probiotic strains or strains with probiotic potential were again from the genus Lactobacillus. Some assays included bifidobacteria and bacteria from the genus Pediococcus and Lactococcus. The most common pathogens included in the assays were 
again S. aureus, L. monocytogenes, E coli, Vibrio spp., Aeromonas spp. Salmonella spp. and Pseudomonas aeruginosa. One study even assessed the antagonistic activity of probiotics against herpes simplex virus types 1 and 2 and one study investigated the antimicrobial activity of probiotics against the protozoa Giardia lamblia. However, using cell-free supernatants does not mimic real conditions. Therefore, further assays are necessary.

\begin{tabular}{|c|c|}
\hline $\begin{array}{l}\text { Probiotic strains or strains with probiotic } \\
\text { potential with efficient antimicrobial } \\
\text { activity in vitro }\end{array}$ & Indicator pathogenic microorganisms \\
\hline
\end{tabular}

Lb:L. acidophilus PBS066, L. fermentum

G+:S. aureus ATCC 6538, E. faecalis ATCC 29212, G-: E. coli

[29]

PBS073,

ATCC 25922, P. aeruginosa ATCC 9027, fng: C. albicans ATCC

L. plantarum PBS067, L. rhamnosus PBS070, L. 10231

reuteri $\mathrm{PBS} 072, \mathrm{Bb}: B$. animalis subsp. lactis

PBS075, B. longum subsp. longum PBS108

Lb:L. salivarius JM41, JK21V, JM31, JS2A,

JM14, JK22, JM2A1 and JM32, L. plantarum

G+:S. aureus ATCC 29213, G-: E. coli K88, 25922 and 1569, S.

PZ01 Oth: P. acidilactici JM241 and JH231, P.

pentosaceus JS233, E. faecium JS11

Lb:L. casei

C1, L. plantarum C4, L. acidophilus

Enteritidis ATCC 13076, S. Typhimurium ATCC 14082

Lb:Lactobacillus MSMC64-1

G+:L. monocytogenes, G-:E. coli C17, S. enterica ser Typhimurium [35]

CECT4156, Y. enterocolitica IP383

LiLertobacillus MSMC64-1

G+: MRSA DMST 20651, 20654, G-: S. Typhi DMST 5784, V.

parahaemolyticus DMST 5665, S. dysenteriae DMST 15111

Lb:L. acidophilus La-5, Bb: B. longum

G+:S. aureus, L. monocytogenes, G-:E. coli O157:H7

ATCC15707

Lb:L. plantarum WCFS1, L. plantarum NA7

G+:L. monocytogenes CIP 81.3 ILSI NA 39, G-: E. coli O157:H7

ATCC 43888, S. enterica ser Enteritidis CIP 81.3

Lb:L. casei PTCC 1608, L. rhamnosus PTCC G-:P. aeruginosa PTCC 1430 1637

Oth:B. amyloliqufaciens

$\mathrm{G}+$ :C. difficile

Oth:P. pentosaceus KID7

G+:S. aureus KCCM1133515, MRSA CCM40510, S. epidermidis

KCTC 191712, L. monocytogenes KACC1076420, B. cereus

KACC11240 G-: S. Typhi KCTC2514, S. choleraesuis

KCTC293215, S. gallinarum KCTC293126, S. boydii KACC10792

14, Y. enterocolitica KACC1532020, E. coli O138KCTC261511,

O1KCTC2441, P. aeruginosa KCCM 1180218,

Lb:L. rhamnosus FM13, FM14, FM22, FS2, G+:S. aureus ATCC 6538, L. monocytogenes DSM 12464, E.

FS10, PS2, PS11, SF6, SP13, L. paracasei CM1, faecalis, G-: E. coli ATCC 25922

CM2, MF5, PM8

Lb: L. casei LC-01, L. acidophilus LA-5, L.

fng:A. niger PTCC 5012, A. flavus PTCC 5004, A. parasiticus paracasei

PTCC 5286, P. chrysogenum PTCC 5035 


\section{Probiotic strains or strains with probiotic potential with efficient antimicrobial activity in vitro}

Indicator pathogenic microorganisms

Reference

Lb:L. viridescens NRRL B-1951

G+:L. monocytogenes CWD 1002, CWD 1198

Lb:L. plantarum S2

G+:S. aureus CMCC2607, G-: E. coli CMCC44825,

S. Typhimurium CMCC50115, S. flexneri CMCC51061

Oth:B. subtilis JQ302302, B. aerophilus JQ312663 JX136697, JX136698, A. enteropelogenes JX136699, P. rettgeri JX 136696

Lb:L. acidophilus L-1, L. bulgaricus 6, L. $\quad$ G+:S. aureus, B. cereus plantarum 24-4B, L. fermentum 1, L. brevis, Bb: G-:E. coli

B. animalis subsp. lactis $\mathrm{L}-3$

Lb:L. plantarum DK211, DK303; L. paracasei

G+:S. aureus KCTC 3881, E. faecalis KCTC 2011, B. cereus KCTC [62] DK215, L. sakei DK301 3624

Lb: L. mesenteroides subsp. mesenteroides SD1, G+:S. aureus ATCC 25923, FRI 184, L. monocytogenes ATCC $\mathrm{SD} 23, \mathrm{SF} 2, \mathrm{SF} 3$ 19115, G-: E. coli ATCC43895, S. enterica ATCC 14028

Oth:L. mesenteroides MTCC 5442, B. subtilis

G-: V. cholerae

Lb:L. fermentum M059, L. fermentum F-6,

G+:S. aureus ATCC 6538, B. cereus NCIM 245, B.

Oth: W. cibaria 4213 subtilis ATCC 6633, G-: E. coli ATCC 25922, S. Typhi 25, P. aeruginosa ATCC 27853

Lb:L. brevis DT24

G-:E. coli MTCC 729

Lb:L. rhamnosus (4 strains)

G-:Helicobacter pylori

Lb:L. plantarum, L. salivarius

G+:S. aureus ATCC 6538S, C. perfringens ATCC 13124, G-: E. coli [68] ATCC 8734, S. Enteritidis ATCC 13311, R. anatipestifer ATCC 11845, P. multocida ATCC 43137

Lb:L. acidophilus P106, L. plantarum P164

Prs:Giardia lamblia

G-: S. flexneri, S. sonnei

G+:S. aureus MTCC737, G-: E. coli MTCC443, S.

Typhimurium MTCC733, S. fleksneri MTCC1457, P. aeruginosa MTCC1688

Lb:L. salivarius K35, K43

G+:S. mutans ATCC 25175

Vr: Herpes simplex virus types 1 and 2

G-:E. tarda, A. hydrophila, V. harveyi, V. parahaemolyticus

Where probiotics are divided as follows: lb: lactobacilli; bb: Bifidobacterium; oth: other; and pathogens are divided as follows: G+: Gram positive; G-: Gram negative; fng: fungi; prs: parasite.

Table 2. A selection of assays published since 2013 of successful antimicrobial activity of chosen probiotics using the agar well diffusion assay or the paper disc assay on chosen pathogenic microorganisms. 


\subsection{Recent results of selected co-culturing assays}

The influence of the potential pathogenic bacteria P. aeruginosa ATCC 27853 against various combinations of probiotic supplements and the kefir microbiota was investigated using the co-culturing method [6]. One multispecies, one oligospecies and one monospecies probiotic supplement as well as kefir microbiota from kefir grains originally from the Caucasian mountains were used. The multispecies supplement contained L. acidophilus (NIZO 3678; NIZO 3887), L. paracasei NIZO 3672, L. plantarum NIZO 3684, L. rhamnosus NIZO 3689, L. salivarius NIZO 3675, B. bifidum NIZO 3804, B. lactis NIZO 3680 and E. faecium NIZO 3886. The oligospecies supplement contained L. acidophilus LA-5, B. infantis BB-12 and E. faecium. The monospecies supplement contained L. reuteri DSM 17938. Co-culturing was conducted by adding $1 \mathrm{~mL}$ of probiotic samples and $1 \mathrm{~mL}$ of overnight $P$. aeruginosa suspension in $40 \mathrm{~mL}$ previously sterilized bovine milk. Samples were incubated for 4 days at $25^{\circ} \mathrm{C}$ with agitation (250/min). After incubation, serial 10-fold dilutions were prepared for all samples and the $P$. aeruginosa populations were enumerated on cetrimide agar with added glycerol. It was found that the P. aeruginosa population in milk without probiotics reached an average of $9.2 \mathrm{log} / \mathrm{mL}$, whilst the $P$. aeruginosa population in milk reached 5.2, 8.3, 8.3 and 5.0 for the samples with the multispecies, oligospecies and monospecies probiotic supplement as well as the kefir microbiota respectively. This research thus found that the decrease of the potential pathogen $P$. aeruginosa was dependent on the type of probiotic microbiota and that both multispecies microbiota (multispecies probiotic supplement kefir microbiota) with a much more diverse population than the other two samples (oligospecies probiotic supplement and the monospecies supplement) exhibited an efficient synergistic effect [7]. Both samples also exhibited a higher increase in the total population of anaerobic microorganisms after fermentation with $P$. aeruginosa thus indicating that a more successful quorum-sensing regulatory network was established and yielded antagonistic effects against the potential pathogen $P$. aeruginosa.

Tharmaraj and Shah [16], as already mentioned in the previous section, also investigated the inhibition effect of various probiotics against chosen pathogenic and spoilage bacteria with the co-culturing method. Briefly, $9 \mathrm{~mL}$ of reconstituted skim milk was inoculated with $1 \mathrm{~mL}$ of overnight culture of probiotic bacteria and $0.1 \mathrm{~mL}$ of pathogenic or spoilage bacteria. The medium was mixed well and incubated at $37^{\circ} \mathrm{C}$ for $24 \mathrm{~h}$. / were counted on nutrient agar and the log population calculated (Table 6). All four pathogenic bacteria were inhibited by all probiotic strains tested to varying degrees. On average, the probiotic bacteria reduced the population of pathogenic bacteria by $2.8 \mathrm{log}$ units. B. cereus was inhibited to a greater degree by all probiotic bacteria and strains than other pathogenic bacteria. On average, the inhibitory effect of all probiotic bacteria and strains was the weakest against E. coli. S. aureus was inhibited to a greater degree by B. animalis and L. rhamnosus than the other probiotic bacteria.

Ratsep et al. [15] published their research of a microtitre plate assay on the antimicrobial effect of L. plantarum (five strains: N11, N27, N33, N44 and E) supernatant against various C. difficile strains (six clinical isolates from Norwegian patients, six clinical isolates from Estonian patients and two reference strains: VPI 10463 and M13042). Overnight C. difficile cultures were added to $\mathrm{BHI}$ broth with a density according to McFarland 3.0. Various reaction mixes were prepared (natural (acidic), neutral ( $\mathrm{pH}$ 6.0) and neutral, heated for $20 \mathrm{~min}$ at $100^{\circ} \mathrm{C}$ ) and incubat- 
ed under anaerobic conditions for $48 \mathrm{~h}$ at $37^{\circ} \mathrm{C}$. The optical density at $620 \mathrm{~mm}$ was measured at the beginning of incubation and after $48 \mathrm{~h}$ and the suppressive activity of L. plantarum strains calculated as a percentage of inhibition. The highest inhibitions of $C$. difficile growth were in the samples of heated neutralized supernatants and the lowest in cases of the neutralized samples. There was statistically higher inhibition in heated neutralized supernatants versus neutralized supernatants of N11 and E56 lactobacilli strains. When comparing antagonistic activity of L. plantarum strains, there was a relevant difference only between N11 and N33 strains in the samples of heated neutralized supernatants. The neutralization of supernatant did not reduce its inhibitory effect. Thus, lowering the $\mathrm{pH}$ of the environment is not the main mechanism in inhibition of $C$. difficile by lactobacilli. Also heating of supernatant did not reduce its activity; thus, some thermostable compounds may be involved in the inhibition. The abovementioned authors [15] also performed the co-culturing assay with the L. plantarum strains and C. difficile strains by inoculating $50 \mathrm{~mL}$ of brain heart infusion broth with $50 \mu \mathrm{L}$ of lactobacilli suspension and $50 \mu \mathrm{L}$ of $C$. difficile suspension and incubating under anaerobic conditions for $48 \mathrm{~h}$ at $37^{\circ} \mathrm{C}$. After incubation, serial 10-fold dilutions were prepared and the C. difficile populations were enumerated on fastidious anaerobe agar. It was found that the five $L$. plantarum strains (N11, N27, N33, N44 and E) were able to inhibit the growth of the 14 C. difficile strains (six clinical isolates from Norwegian patients and Estonian patients and two reference strains: VPI 10463, M13042) in the co-culture incubation as the average log cfu/mL after $48 \mathrm{~h}$ was 3.0, whereas the average $\log \mathrm{cfu} / \mathrm{mL}$ of the $C$. difficile strains alone was 7.0.

Another important co-culturing method is the use of cell lines as noted in the research by Abdel et al. [31] of 12 lactobacilli isolates interfering with the adherence and invasion of S. Typhi 66 using kidney epithelial cell line Vero (ATCC CCl-81). The same authors also investigated this interference with the co-culturing assay in MRS broth. It was found that nine lactobacilli isolates inhibited the growth of $S$. Typhi in the co-culturing assay. Nine lactobacilli isolates were also successful in achieving a $>50 \%$ inhibition of adherence of $S$. Typhi isolate (SS6) to Vero cells.

Assays published since 2013 of antimicrobial activity of chosen probiotics using various coculturing assays on chosen pathogenic microorganisms are noted in Table 3 . The results were similar to the results of spot-on lawn and agar well diffuse assays.

\begin{tabular}{lr}
\hline Probiotic strains or strains with probiotic potential Indicator pathogenic microorganisms & Reference \\
with efficient antimicrobial activity in vitro &
\end{tabular}

Lb:L. plantarum FH185 G+:S. aureus, G-:S. Typhimurium [9]

Lb:L. acidophilus La-5, Bb: B. longum ATCC15707

G+:S. aureus, L. monocytogenes, G-:E. coli O157:H7 
Probiotic strains or strains with probiotic potential Indicator pathogenic microorganisms

Reference

with efficient antimicrobial activity in vitro

Lb:L. reuteriOth:B. subtilis MA139

G-: E. coli $\mathrm{K} 88$

[77]

Lb:L. plantarum C014

G-:A. hydrophila TISTR 1321

[78]

Lb:L. acidophilus, Oth:Pediococcus

G-:S. Enteritidis 13A

[79]

Lb:L. paracasei CNCM I-4034, L. rhamnosus CNCM

G-:E. coli ETEC CECT 501, S. Typhimurium CECT

[80]

I-4036, Bb: B. breve CNCM I-4035

443 S. Typhi CECT 725, S. sonnei CECT 457

Lb:L. fermentum 907, Bb: B. longum 1011

G-:E. coli O157:H7, E. coli O86

$[81]$

Where probiotics are divided as follows: lb: lactobacilli; bb: Bifidobacterium; and pathogens are divided as follows: G+: Gram positive; G-: Gram negative; fng: fungi; prs: parasite.

Table 3. A selection of assays published since 2013 of successful antimicrobial activity of chosen probiotics using the co-culturing assay on chosen pathogenic microorganisms.

\section{Recent results of in vivo antimicrobial/antagonistic assays for various probiotic strains}

\subsection{Recent results of determining the in vivo antimicrobial assays using animal models}

In the research by Mazaya et al. [36], both in vitro and in vivo studies were conducted. The significant in vitro antimicrobial activity (no method specified) of two lactobacillus strains isolated from Egyptian dairy products (L. plantarum LA5 and L. paracasei LA7) was found against several potential pathogens: S. aureus ATCC 25923, B. subtilis ATCC 23857, M. luteus ATCC 21882, P. aeruginosa ATCC 27853 and S. Typhi. In vivo assays were also conducted on 5 -week-old male mice, divided into six groups (10 mice/group). Animals within different treatment groups were treated daily for 8 days as follows: Group 1, untreated control; Group 2, animals challenged with single inoculation S. Typhi (200 $\mu \mathrm{L}$ aliquot of 1 X 108/P.O); Group 3, animals treated orally with L. plantarum (LA5) (200 $\mu \mathrm{L}$ aliquot of 1 X 108/P.O) for 7 days; Group 4, animals treated orally with L. paracasei (LA7) (200 $\mu \mathrm{L}$ aliquot of 1X 108/P.O) for 7 days; Group 5, animals challenged with single inoculation $S$. Typhi, then treated with LA5 for next 7 days; Group 6, animals challenged with single inoculation $S$. Typhi and treated with LA 7 for next 7 days. Administration of LA5 or LA7 counteracted the pathogenic effect resulting from Salmonella infection. The lactobacilli succeeded to get rid of salmonellosis based on its phagocytic and immunostimulant activity against typhoid antigen.

Lazarenko et al. [82] conducted an in vitro and in vivo assay to determine anti-staphylococcal actions of certain probiotic cultures (L. casei IMV B-7280, L. acidophilus IMV B-7279; B. longum VK1 and B. bifidum VK2). In vitro assay using perpendicular strokes yielded antagonistic activity against all three strains of $S$. aureus (209-P, 43, 8325-4). The in vivo study with S. aureus 8325-4 on mice showed that the combination of probiotics (L. casei IMV B-7280, B. longum VK1 and B. bifidum VK2) was most successful as after day 9 no colonies of S. aureus 8325-4 were found in the vagina of the mice. 
In the study by Bujalance et al. [35], a lack of correlation between in vitro and in vivo methods of the antimicrobial activity of probiotic lactobacilli against enteropathogenic bacteria was determined. In this study, the in vitro assay using the agar spot test showed that 20 strains of probiotic lactobacilli successfully inhibited Y. enterocolitica, S. enterica ser Typhimurium and $L$. monocytogenes. However, in the in vivo study using mouse models the selected strains (L. casei $\mathrm{C} 1$ and L. plantarum C4) lacked protective effects against S. Typhimurium. Similar conclusions of finding no antagonism in vivo are noted in the study by Bratz et al. [83]. Another study [79] found that the tea Yerba mate exhibited antagonistic activity in vitro but as a feed additive did not reduce S. Enteritidis colonization in vivo in broiler chickens. These studies prove that successful in vitro assays do not necessarily mean that the chosen microorganism with probiotic properties will be successful in real conditions. On the other hand, in vivo animal studies do not automatically prove antagonism in humans or other species. Therefore, the justification of using vertebrate animal models is questionable [32]. Gupta et al. [84] used Drosophila melanogaster commonly known as the "fruit fly," instead of a vertebrate animal model. It is a eukaryotic organism and is considered an alternative in the drug discovery process, mainly because the key physiological processes are well conserved from fly to humans. Moreover, a short life cycle, distinct developmental stages, easy cultivation, numerous offspring and a strong cytogenetic/genetic background make Drosophila a model organism to study many biological processes including toxicity testing. Zhou et al. [30] used porcine neonatal jejunal epithelial cell lines (IPEC-J2) for in vitro assay and worms (Caenorhabditis elegans) for in vivo testing of lactobacilli isolates against enterotoxigenic E. coli

\begin{tabular}{llc}
\hline $\begin{array}{l}\text { Probiotic strains or strains with probiotic } \\
\text { potential with efficient antimicrobial activity } \\
\text { in vivo using animal models }\end{array}$ & Indicator pathogenic microorganisms & Reference \\
\hline Lb:L. reuteri CL9, K16, K67 and S33 & & [30] \\
Lb:L. salivarius JM32, L. plantarum PZ01 Oth: & G-:E. coli O149: K88 JG280 & [34] \\
$\begin{array}{l}\text { P. acidilactici JH231 } \\
\text { Lb:L. plantarum LA5 and L. paracasei LA7 }\end{array}$ & G-:S. Enteritidis ATCC 13076 & [36] \\
Oth:B. amyloliqufaciens & G-:S. Typhi & [54] \\
Lb:L. plantarum C014 & G+:C. difficile & [78] \\
Lb:L. casei B-7280, Bb: B. longum VK1, B. bifidumVK2 & G-:A. hydrophila TISTR 1321 & [82] \\
Lb:L. plantarum LR/14 & G+: S. aureus8325-4 & [84] \\
Lb:L. acidophilus CH1 & Ins:Drosophila melanogaster & {$[85]$} \\
Oth:Pseudoalteromonas sp. & Prs:Enterocytozoon bieneusi \\
\hline
\end{tabular}

Where probiotics are divided as follows: lb: lactobacilli; bb: Bifidobacterium; oth: other; and pathogens are divided as follows: G+: Gram positive; G-: Gram negative; fng: fungi; prs: parasite; ins: insect.

Table 4. A selection of assays published since 2013 of successful antimicrobial activity of chosen probiotics using the in vivo animal models on chosen pathogenic microorganisms. 
The most recent in vivo antagonistic assays using animal models are noted in Table 4 . These results confirm the strain specific antagonistic activity of chosen probiotics.

\subsection{Recent results of determining the in vivo antimicrobial assays using clinical trials}

Most important research on the antagonistic effect of probiotics are clinical trials, however only a few well conducted clinical studies have been reported. Most clinical studies include the comparison of antibiotic therapy with adjuvant probiotic therapy. In the study by Dore et al. [87], in this prospective, single centre, open label pilot study, patients scheduled for upper endoscopy for any reason and found to be positive for $H$. pylori infection were invited to enter. The intervention consisted of L. reuteri (DSM 17938, Reuflor, BioGaia AB, Sweden) $10^{8} \mathrm{cfu} /$ tablet plus pantoprazole (proton pump inhibitor) $20 \mathrm{mg}$ twice a day. A 76\% decrease in urease activity was observed. The absence of a control group with pantoprazole without L. reuteri however prevents any definite conclusion.

In the study by Pendharkar et al. [88] the clinical outcome for women conventionally treated for bacterial vaginosis and yeast infection with probiotics bacilli was investigated. This study is an example of the antibiotic therapy with adjuvant probiotic therapy. In the clinical trial, women were recruited in three groups as follows: women with bacterial vaginosis receiving clindamycin and metronidazole treatment together with a prolonged administration of EcoVag $^{\circledR}$ (containing L. rhamnosus DSM 14870 and L. gasseri DSM 14869) for 10 consecutive days after each antibiotic treatment followed by weekly administration of capsules for next four months, women with recurrent vulvovaginal candidiasis receiving extended fluconazole and EcoVag ${ }^{\circledR}$ treatment, and women receiving extended fluconazole treatments only. The 6- and 12-month cure rates for bacterial vaginosis were $67 \%$. The 6 - and 12-month cure rates for vulvovaginal candidiasis were 100 and $89 \%$ in women receiving fluconazole and $\mathrm{EcoVag}^{\circledR}$, and 100 and $70 \%$ in women receiving fluconazole only. The study suggests that the treatment with antibiotics or anti-fungal medication in combination with EcoVag ${ }^{\circledR}$ capsules provide long-term cure against bacterial vaginosis and R-VVC.

Some of the most recent in vivo antagonistic clinical trials are noted in Table 5. These results confirm that adjuvant therapy with antibiotics and chosen probiotics enhances the antagonistic activity.

\begin{tabular}{|c|c|c|c|c|}
\hline $\begin{array}{l}\text { Probiotic strains with efficient } \\
\text { antimicrobial activity using in vivo } \\
\text { clinical trials and other therapies }\end{array}$ & $\begin{array}{l}\text { Pathogenic } \\
\text { microorganisms or } \\
\text { treated disease }\end{array}$ & Basic therapy & $\begin{array}{l}\text { Type of } \\
\text { trial }\end{array}$ & Reference \\
\hline Lb:L. reuteri DSM 17938 & G+:H. pylori & $\begin{array}{l}\text { Proton pump inhibitor: } \\
\text { pantoprazole }\end{array}$ & $\mathrm{CT}$ & [87] \\
\hline $\begin{array}{l}\text { Lb:L. rhamnosus DSM 14870, L. gasseri } \\
\text { DSM } 14869\end{array}$ & $\begin{array}{l}\text { Bc: not specified, Fng: } \\
\text { Candida spp. }\end{array}$ & $\begin{array}{l}\text { Antibiotics: Clindamycin, } \\
\text { metronidazole, fluconazole }\end{array}$ & CT & {$[88]$} \\
\hline $\begin{array}{l}\text { Lb:L. rhamnosus GG (LGG), Bb: } B \text {. } \\
\text { bacterium BB-12 }\end{array}$ & G+:H. pylori & $\begin{array}{l}\text { Standard triple H. pylori } \\
\text { eradication therapy with }\end{array}$ & DBRCT & [89] \\
\hline
\end{tabular}




\begin{tabular}{|c|c|c|c|c|}
\hline $\begin{array}{l}\text { Probiotic strains with efficient } \\
\text { antimicrobial activity using in vivo } \\
\text { clinical trials and other therapies }\end{array}$ & $\begin{array}{l}\text { Pathogenic } \\
\text { microorganisms or } \\
\text { treated disease }\end{array}$ & Basic therapy & $\begin{array}{l}\text { Type of } \\
\text { trial }\end{array}$ & Reference \\
\hline & & $\begin{array}{l}\text { antibiotics: omeprazole, } \\
\text { pantoprazole, clarithromycin, } \\
\text { amoxicillin, or metronidazole }\end{array}$ & & \\
\hline $\begin{array}{l}\text { Lb:L. rhamnosus GG (LGG), L. } \\
\text { acidophilus La-5, Bb: B. bacterium BB- } 12\end{array}$ & Dis: AAD & $\begin{array}{l}\text { Antibiotics: broad spectrum } \\
\text { oral antibiotics }\end{array}$ & DBRCT & [90] \\
\hline $\begin{array}{l}\text { Lb:L. acidophilus, L. paracasei } \mathbf{B b} \text { :B. lactis } \\
\text { At: bismuth }\end{array}$ & $\mathrm{G}+:$ H. pylori & $\begin{array}{l}\text { Antibiotics: broad spectrum } \\
\text { oral antibiotics: lansoprazole, } \\
\text { amoxicillin, clarithromycin }\end{array}$ & BDRCT & [91] \\
\hline Lb:L. casei DN-114001 & Dis: AAD & $\begin{array}{l}\text { Antibiotics: broad spectrum } \\
\text { oral antibiotics }\end{array}$ & $\mathrm{CT}$ & {$[92]$} \\
\hline $\begin{array}{l}\text { Lb:L. acidophilus, l. rhamnosus, L. } \\
\text { acidophilus, L. bulgaricus, Bb:B. } \\
\text { bifidusOth:S. Thermophilus }\end{array}$ & Dis: bacterial vaginosis & Antibiotic: metronidazole & $\mathrm{CT}$ & [93] \\
\hline
\end{tabular}

Where probiotics are divided as follows: lb: lactobacilli; $\mathrm{bb}$ : Bifidobacterium; oth: other; pathogens are divided as follows: bc: bacteria; G+: Gram positive; G-: Gram negative; fng: fungi; and clinical trials are divided as follows: DBRCT: doubleblinded randomized clinical trial; CT: clinical trial; AT: additional therapy; Dis: disease; AAD: antibiotic associated diarrhoea.

Table 5. A selection of published since 2013 of antimicrobial activity of chosen probiotics using in vivo clinical trials on chosen pathogenic microorganisms or treatment of diseases.

\section{Discussion and conclusions}

The antimicrobial ability of probiotics is a very important trait and includes the production of antimicrobial compounds, competitive exclusion of pathogens, enhancement of the intestinal barrier function and others. Usually, probiotic strains produce more than one antimicrobial substance that may act synergistically, increasing the spectrum of targeted microorganisms. This property may be desirable as long as this antimicrobial spectrum is restricted to pathogenic microorganisms but it cannot be excluded that it will not affect the normal microbiota of the gut or other microbiotas as well [94]. The results show that probiotic properties are strain dependent and that strain identification is imperative [3].

Probiotic candidates have been accessed from very diverse habitats including faeces of breastfed human infants $[65,69,80,85,95]$, faeces of healthy adults $[9,15,65,70]$, faeces of elderly [81], faeces of children [25, 96], breast milk [42], human saliva [52], vaginal isolates of healthy women [66, 75], various fermented foods or beverages including raw or fermented milk [23, 35, 44], kefir [97], cheese [51, 56, 98], whey [99], yogurt [16, 41], dahi [100, 101], other dairy products [25, 36, 61], sourdough [102], sausages [17], fermented meat [24], kimchi [10, 62], maize [25, 59], fermented olives [103], Yerba mate [79], ragi [64], soy sauce [86], soil [104], as 
well as animal origin including rat faeces [71], geese [68], calves [105], pigs [45], fish [39, 60, $63,78]$ and other seafood $[40,43,46]$ and many others.

By far, the most commonly investigated probiotic were bacteria of the genus Lactobacillus ( $L$. plantarum, L. acidophilus, L. fermentum, L. casei, L. paracasei and L. reuteri). The genus Bifidobacterium and other probiotic microorganisms (Lactococcus, Pediococcus, Enterococcus, Bacillus and Saccharomyces) have been also been investigated, but to a somewhat lesser extent. Studies were also conducted on known probiotics from various tissue type collections. The most common pathogens used to test the antagonistic activity of probiotics were different strains of S. aureus, E. faecium, E. faecalis, L. monocytogenes, E. coli, various Salmonella, Vibrio and Yersinia spp., and $\mathrm{P}$. aeruginosa.

The antimicrobial activity of probiotic microorganisms has a very wide area application including adjuvant therapy to antibiotic consumption or for correcting dysbiosis of the gastrointestinal tract microbiome due to diarrhoea $[37,38,106]$, antagonistic activity in humans against urinary tract infections [26, 66, 75], eradicating H. pylori infections [87], nosocomial infections [15, 96], dental biofilm formation [72], lowering serum cholesterol [10, 55], treating fevers [31], as well as in the agro-food industry for manufacturing fermented products [44, 62, 107], preventing food spoilage [16, 23, 41], as food additives for functional foods [50, 56, 57, $59,67,97]$, as prophylactic agents, adjuvants or alternatives to antibiotic therapies to antibiotic therapy in poultry $[34,47,68]$, cattle [105, 108], pigs [45], fish [74, 78] and other livestock industry [104], just to name a few.

The process of determining antimicrobial properties of probiotic is complex and includes in vitro assays, in vivo models or substitute models, clinical studies, metagenomic analyses and mathematical modelling. Only after all these steps are completed, a probiotic candidate can be identified as such [109]. In vitro studies are the most represented. Although, they are a crucial step in selecting probiotic candidates, they are only the first step as efficient antimicrobial activity via in vitro studies does not necessarily mean that the antimicrobial activity is present in in vivo assays. Therefore, further research methods (double-blinded randomized clinical trials) are necessary to prove the important antimicrobial trait of probiotic candidates. As noted in Section 5.2, there are only a few well-conducted published clinical studies. Most clinical studies include the comparison of antibiotic therapy with adjuvant probiotic therapy which is an important aim of probiotic consumption.

There is a clear need for more elaborate assays that would better represent the complex interactions between the probiotics and the host microbiome to understand the consequences of the in situ production of antimicrobials by the former [94]. Another important fact is that probiotics are often found to have higher antagonist activity as multispecies groups [6, 7, 26]. Quorum sensing among probiotics is also an important factor; however, quorum-sensing studies among probiotics are sparse. It is well known that microorganisms coordinate collective behaviour in response to environmental challenges using sophisticated intercellular communication networks and that they are not limited to communication within their own species but are capable of intercepting messages and coerce cohabitants into behavioural modifications [110], therefore probiotics are included. Although all these facts make re- 
search of the antimicrobial/antagonistic activity of probiotics even more complex, it also presents a great opportunity for future research.

\section{Author details}

Sabina Fijan

Address all correspondence to: sabina.fijan@um.si

Faculty of Health Sciences, University of Maribor, Maribor, Slovenia

\section{References}

[1] Peterson J, Garges S, Giovanni M, McInnes P. The NIH human microbiome project. Genome Res. 2009;19:2317-2323.

[2] Rijkers GT, De Vos WM, Brummer RJ, Morelli L, Corthier G, Marteau P. Health benefits and health claims of probiotics: bridging science and marketing. Br J Nutr. 2011;106:1291-1296.

[3] Fijan S. Microorganisms with claimed probiotic properties. Int J Environ Res Public Health. 2014;11:4745-4767.

[4] Food and Agriculture Organization of the United Nations/World Health Organization FAO/WHO. Health and Nutritional Properties of Probiotics in Food including Powder Milk with Live Lactic [Internet]; 2001. Available from: http://www.who.int/ foodsafety/publications/fs_management/en/probiotics.pdf [Accessed: 11.1.2016]

[5] Working Group on Drafting Guidelines for the Evaluation of Probiotics in Food. Guidelines for the Evaluation of Probiotics in Food; Joint FAO/WHO. London, Ontario, Canada: Food and Agriculture Organization of the United Nations/World Health Organization FAO/WHO; 2002.

[6] Fijan S. Influence of the growth of Pseudomonas aeruginosa in milk fermented by multispecies probiotics and Kefir microbiota. J Probiotics Health. 2016;3:136. DOI: 10.4172/2329-8901.1000136.

[7] Koning CJ, Jonkers D, Smidt H, Rombouts F, Pennings HJ, Wouters E, Stobberingh E, Stockbrügger R. The effect of a multispecies probiotic on the composition of the faecal microbiota and bowel habits in chronic obstructive pulmonary disease patients treated with antibiotics. Br J Nutr. 2010;103:1452-1460.

[8] He F, Morita H, Ouwehand AC. Bifidobacteria and lactobacilli exhibited different mitogenic activity on murine splenocytes. Int J Probiotics Prebiotics. 2006;1:77-82. 
[9] Park S-Y; Lim S-D. Probiotic characteristics of Lactobacillus plantarum FH185 isolated from human feces. Korean J Food Sci. 2015;35(5):615-621.

[10] Choi EA, Chang HC. Cholesterol-lowering effects of a putative probiotic strain Lactobacillus plantarum EM isolated from kimchi. LWT - Food Sci Technol. 2015;62(1): 210-217.

[11] Sanders ME. Probiotics: definition, sources, selection, and uses. Clin Infect Dis. 2008;46(2):S58-S61. DOI: 10.1086/523341.

[12] Sanders ME. Summary of probiotic activities of Bifidobacterium lactis HN019. J Clin Gastroenterol. 2006; 40:776-783.

[13] Saxelin M, Tynkkynen S, Mattila-Sandholm T, de Vos WM. Probiotic and other functional microbes: from markets to mechanisms. Curr Opin Biotechnol. 2005;16:204211.

[14] Millette M, Luquet FM, Lacroix M. In vitro growth control of selected pathogens by Lactobacillus acidophilus - and Lactobacillus casei-fermented milk. Lett Appl Microbiol. 2007;44:314-319.

[15] Ratsep M, Naaber P, Koljalg S, Smidt I, Shkut E, Sepp E. Effect of Lactobacillus plantarum strains on clinical isolates of Clostridium difficile in vitro. J Probiotics Health. 2014;2:119.

[16] Tharmaraj N, Shah N P. Antimicrobial effects of probiotics against selected pathogenic and spoilage bacteria in cheese-based dips. Int Food Res J. 2009;16:261-276.

[17] Ammor S, Tauveron G, Dufour E, Chevallier I. Antibacterial activity of lactic acid bacteria against spoilage and pathogenic bacteria isolated from the same meat smallscale facility. Food Control. 2006;17:454-461.

[18] Arqués JL, Rodríguez E, Langa S, Landete JM, Medina M. Antimicrobial activity of lactic acid bacteria in dairy products and gut: effect on pathogens. BioMed Res Int. 2015;2015:9. DOI: 10.1155/2015/584183.

[19] Šušković J, Kos B, Beganovič J, Leboš Pavunc A, Habjanič K, Matošić S. Antimicrobial activity - the most important property of probiotic and starter lactic acid bacteria. Food Technol Biotechnol. 2010;48(3):296-307.

[20] Tagg JR, Dajani AS, Wannmaker LW. Bacteriocines of gram positive bacteria. Bacteriol Rev. 1976;40:722-756.

[21] Hoover DG, Harlander SK. Screening methods for detecting bacteriocin activity. In: Hoover DG, Steenson LR, editors. Bacteriocins of lactic acid bacteria. San Diego: Academic Press; 1993. p. 23-29.

[22] Parente E, Brienza C, Moles M, Ricciardi A. A comparison of methods for the measurement of bacteriocin activity. J Microbiol Methods. 1995;22:95-108. 
[23] Soomro AH, Musad T, Sammiand S, Rathore HA. Comparison of different methods for detection of antimicrobial activity of Lactobacillus spp. Pakistan J Zool. 2007;39(4):265268.

[24] Pilasombut K, Rumjuankiat K, Ngamyeesoon N, Duy le ND. In vitro characterization of bacteriocin produced by lactic acid bacteria isolated from Nem Chua, a traditional Vietnamese fermented pork. Korean J Food Sci Anim. 2015;35(4):473-478.

[25] Jacobsen CN, Rosenfeldt Nielsen V, Hayford AE, Møller PL, Michaelsen KF, Paerregaard A, Sandström B, Tvede M, Jakobsen M. Screening of probiotic activities of fortyseven strains of Lactobacillus spp. by in vitro techniques and evaluation of the colonization ability of five selected strains in humans. Appl Environ Microbiol. 1999;65:4949-4956.

[26] Chapman CM1, Gibson GR, Rowland I. In vitro evaluation of single- and multi-strain probiotics: inter-species inhibition between probiotic strains, and inhibition of pathogens. Anaerobe. 2012;18(4):405-413. DOI: 10.1016/j.anaerobe.2012.05.004.

[27] Fijan S, Šostar Turk, S. Influence of the microbial community in Kefir Grains on the survival and growth of Staphylococcus aureus in Milk. Abstracts from the meeting: 7th Probiotics, prebiotics \& new foods, September 8-10 2013; Rome, Iniversità Urbaniana. J Clin Gastroenterol. 2014;48(1):S113-S114.

[28] Fijan S, Trunk M, Šostar Turk S. Influence of the microbial community in kefir grains on the survival and growth of Candida albicans in milk. In: International scientific conference on probiotics and prebiotics, Budapest, June 24-26, 2014. Kysucké Nové Mesto: Pamida; 2014. p. 89.

[29] Presti I, D'Orazio G, Labra M, La Ferla B, Mezzasalma V, Bizzaro G, Giardina S, Michelotti A, Tursi F, Vassallo M, Di Gennaro P. Evaluation of the probiotic properties of new Lactobacillus and Bifidobacterium strains and their in vitro effect. Appl Microbiol Biotechnol. 2015;99(13):5613-5626. DOI: 10.1007/s00253-015-6482-8.

[30] Zhou M, Zhu J, Yu H, Yin X, Sabour PM, Zhao L, Chen W, Gong J. Investigation into in vitro and in vivo models using intestinal epithelial IPEC-J2 cells and Caenorhabditis elegans for selecting probiotic candidates to control porcine enterotoxigenic Escherichia coli. J Appl Microbiol. 2014;117(1):217-226. DOI: 10.1111/jam.12505.

[31] Abdel-Daim A, Hassouna N, Hafez M, Ashor MS, Aboulwafa MM. Antagonistic activity of Lactobacillus isolates against Salmonella typhi in vitro. Biomed Res Int. 2013;2013:680605. DOI: 10.1155/2013/680605.

[32] Cencič A. Can functional cell models replace laboratory animals in biomedical research? J Bioanal Biomed. 2012;4:e105. DOI: 10.4172/1948-593X.1000e105.

[33] Cencič A, Langerholc T. Functional cell models of the gut and their applications in food microbiology - a review. Int J Food Microbial. 2010;141:S4-S14. DOI: 10.1016/j.ijfoodmicro.2010.03.026. 
[34] Feng J, Wang L, Zhou L, Yang X, Zhao X. Using in vitro immunomodulatory properties of lactic acid bacteria for selection of probiotics against Salmonella infection in broiler chicks. PLoS One. 2016;11(1):e0147630. DOI: 10.1371/journal.pone.0147630.

[35] Bujalance C, Jiménez-Valera M, Moreno E, Ruiz-López MD, Lasserrot A, Ruiz-Bravo A. Lack of correlation between in vitro antibiosis and in vivo protection against enteropathogenic bacteria by probiotic lactobacilli. Res Microbiol. 2014;165(1):14-20. DOI: DOI: 10.1016/j.resmic.2013.10.006.

[36] Mazaya B, Hamzawy MA, Khalil MA, Tawkol WM, Sabit H. Immunomodulatory and antimicrobial efficacy of Lactobacilli against enteropathogenic infection of Salmonella typhi: In-vitro and in-vivo study. Int J Immunopathol Pharmacol. 2015;28(4):469-478. DOI: $10.1177 / 0394632015592099$.

[37] Bendali F1, Madi N, Sadoun D. Beneficial effects of a strain of Lactobacillus paracasei subsp. paracasei in Staphylococcus aureus-induced intestinal and colonic injury. Int J Infect Dis. 2011;15(11):e787-e794. DOI: 10.1016/j.ijid.2011.07.003.

[38] Chimchang J, Theparee T, Ladda B, Tanasupawat S, Wongsatayanon BT, Taweechotipatr M. Antimicrobial properties of a potential probiotic Lactobacillus from Thai newborn feces. J Med Assoc Thai. 2015;98(9):S116-S122.

[39] Pinpimai K, Rodkhum C, Chansue N, Katagiri T, Maita M, Pirarat N. The study on the candidate probiotic properties of encapsulated yeast, Saccharomyces cerevisiae JCM 7255, in Nile Tilapia (Oreochromis niloticus). Res Vet Sci. 2015;102:103-111. DOI: 10.1016/ j.rvsc.2015.07.021.

[40] Liu XF, Li Y, Li JR, Cai LY, Li XX, Chen JR, Lyu SX. Isolation and characterisation of Bacillus spp. antagonistic to Vibrio parahaemolyticus for use as probiotics in aquaculture. World J Microbiol Biotechnol. 2015;31(5):795-803. DOI: 10.1007/s11274-015-18332.

[41] El-Kholy AM, El-Shinawy SH, Meshref AMS, Korny AM. Screening of antagonistic activity of probiotic bacteria against some food-borne pathogens. J Appl Environ Microbiol. 2014;2(2):53-60.

[42] Shokryazdan P,Sieo CC, Kalavathy R, Liang JB, Alitheen NB, Jahromi MF, Ho YW. Probiotic potential of Lactobacillus strains with antimicrobial activity against some human pathogenic strains. BioMed Res Int. 2014;2014:16. DOI: http://dx.DOI.org/ $10.1155 / 2014 / 927268$.

[43] Muñoz-Atienza E, Araújo C, Magadán S, Hernández PE, Herranz C, Santos Y, Cintas LM. In vitro and in vivo evaluation of lactic acid bacteria of aquatic origin as probiotics for turbot (Scophthalmus maximus L.) farming. Fish Shellfish Immunol. 2014;41(2): 570-580. DOI: 10.1016/j.fsi.2014.10.007. 
[44] Mami A, Kerfouf A, Kihal M. Study of the antimicrobial and probiotic effect of Lactobacillus Plantarum isolated from raw goat's milk from the region of Western Algeria. Int J Sci Basic Appl Res. 2014;13(1):18-27.

[45] Han SK, Shin MS, Park HE, Kim SY, Lee WK. Screening of bacteriocin-producing Enterococcus faecalis strains for antagonistic activities against Clostridium perfringens. Korean J Food Sci Anim Resour. 2014;34(5):614-621.

[46] Wu HJ, Sun LB, Li CB, Li ZZ, Zhang Z, Wen XB, Hu Z, Zhang YL, Li SK. Enhancement of the immune response and protection against Vibrio parahaemolyticus by indigenous probiotic Bacillus strains in mud crab (Scylla paramamosain). Fish Shellfish Immunol. 2014;41(2):156-162. DOI: 10.1016/j.fsi.2014.08.027.

[47] Menconi A, Kallapura G, Latorre JD, Morgan MJ, Pumford NR, Hargis BM, Tellez G. Identification and characterization of lactic acid bacteria in a commercial probiotic culture. Biosci Microbiota Food Health. 2014;33(1):25-30. DOI: 10.12938/bmfh.33.25.

[48] Belicova A, Mikulašova M, Dušinsky R. Probiotic potential and safety properties of Lactobacillus plantarum from Slovak Bryndza cheese. Biomed Res Int. 2013;2013:760928. DOI: $10.1155 / 2013 / 760298$.

[49] Chapman CM, Gibson GR, Todd S, Rowland I. Comparative in vitro inhibition of urinary tract pathogens by single- and multi-strain probiotics. Eur J Nutr. 2013;52(6): 1669-1677. DOI: 10.1007/s00394-013-0501-2.

[50] Tulini FL, Winkelströter LK, De Martinis EC. Identification and evaluation of the probiotic potential of Lactobacillus paraplantarum FT259, a bacteriocinogenic strain isolated from Brazilian semi-hard artisanal cheese. Anaerobe. 2013;22:57-63. DOI: 10.1016/j.anaerobe.2013.06.006.

[51] Ali F S, Saad O A O, Salwa AH. Antimicrobial activity of probiotic bacteria. Egypt Acad J Biol Sci. 2013;5(2):21-34.

[52] Aoudia N, Rieu A, Briandet R, Deschamps J, Chluba J, Jego G, Garrido C, Guzzo J. Biofilms of Lactobacillus plantarum and Lactobacillus fermentum: effect on stress responses, antagonistic effects on pathogen growth and immunomodulatory properties. Food Microbiol. 2016;53(Pt A):51-59. DOI: DOI: 10.1016/j.fm.2015.04.009.

[53] Aminnezhad S, Kermanshahi RK, Ranjbar R. Evaluation of synergistic interactions between cell-free supernatant of Lactobacillus Strains and Amikacin and genetamicin against Pseudomonas aeruginosa. Jundishapur J Microbiol. 2015;18(8):e16592. DOI: 10.5812/jjm.8(4)2015.16592.

[54] Geeraerts S, Ducatelle R, Haesebrouck F, Van Immerseel F. Bacillus amyloliquefaciens as prophylactic treatment for Clostridium difficile-associated disease in a mouse model. J Gastroenterol Hepatol. 2015;30(8):1275-1280. DOI: 10.1111/jgh.12957.

[55] Damodharan K, Lee YS, Palaniyandi SA, Yang SH, Suh JW. Preliminary probiotic and technological characterization of Pediococcus pentosaceus strain KID7 and in vivo 
assessment of its cholesterol-lowering activity. Front Microbiol. 2015;6:768. DOI: 10.3389/fmicb.2015.00768.

[56] Caggia C, De Angelis M, Pitino I, Pino A, Randazzo CL. Probiotic features of Lactobacillus strains isolated from Ragusano and Pecorino Siciliano cheeses. Food Microbiol. 2015;50:109-117. DOI: 10.1016/j.fm.2015.03.010.

[57] Abbaszadeh S, Tavakoli R, Sharifzadeh A, Shokri H. Lactic acid bacteria as functional probiotic isolates for inhibiting the growth of Aspergillus flavus, A. parasiticus, A. niger and Penicillium chrysogenum. J Mycol Med. 2015;25(4):263-267. DOI: 10.1016/j.mycmed. 2015.10.011.

[58] Ünlü G, Nielsen B, Ionita C. Production of Antilisterial Bacteriocins from lactic acid bacteria in dairy-based media: a comparative study. Probiotics Antimicrob Proteins. 2015;7(4):259-274. DOI: 10.1007/s12602-015-9200-z.

[59] Yu X, Yin J, Li L, Luan C, Zhang J, Zhao C, Li S. Prebiotic potential of xylooligosaccharides derived from corn cobs and their in vitro antioxidant activity when combined with Lactobacillus. J Microbiol Biotechnol. 2015;25(7):1084-1092. DOI 10.4014/ jmb.1501.01022.

[60] Thankappan B1, Ramesh D, Ramkumar S, Natarajaseenivasan K, Anbarasu K. Characterization of Bacillus spp. from the gastrointestinal tract of Labeo rohita - towards to identify novel probiotics against fish pathogens. Appl Biochem Biotechnol. 2015;175(1):340-353. DOI: 10.1007/s12010-014-1270-y.

[61] Georgievaa R, Yochevab L, Tserovskab L, Zhelezovab G, Stefanovaa N, Atanasovaa A, Dangulevaa A, Ivanovaa G, Karapetkova N, Rumyana N, Karaivanovaa E. Antimicrobial activity and antibiotic susceptibility of Lactobacillus and Bifidobacterium spp. intended for use as starter and probiotic cultures. Biotechnol Biotech Equipm. 2015;29(1):84-91. DOI: 10.1080/13102818.2014.987450.

[62] Baick SC, Kim CH. Assessment of characteristics and functional properties of Lactobacillus species isolated from Kimchi for dairy use. Korean J Food Sci Anim Resour. 2015;35(3):339-349. DOI: 10.5851/kosfa.2015.35.3.339.

[63] Diana CR, Humberto HS, Jorge YF. Probiotic properties of Leuconostoc mesenteroides isolated from Aguamiel of Agave salmiana. Probiotics Antimicrob Proteins. 2015;7(2): 107-117. DOI: 10.1007/s12602-015-9187-5.

[64] VidyaLaxme B, Rovetto A, Grau R, Agrawal R. Synergistic effects of probiotic Leuconostoc mesenteroides and Bacillus subtilis in malted ragi (Eleucine corocana) food for antagonistic activity against $V$. cholerae and other beneficial properties. J Food Sci Technol. 2014;51(11):3072-3082. DOI: 10.1007/s13197-012-0834-5.

[65] Gomathi S, Sasikumar P, Anbazhagan K, Sasikumar S, Kavitha M, Selvi MS, Sadasivam Selvam G. Screening of indigenous oxalate degrading lactic acid bacteria from 
human faeces and South Indian fermented foods: assessment of probiotic potential. Sci World J. 2014;2014:11. DOI: 10.1155/2014/648059.

[66] Trivedi D, Jena PK, Seshadri S. Colicin E2 Expression in Lactobacillus brevis DT24, a vaginal probiotic isolate, against uropathogenic Escherichia coli. ISRN Urol. 2014;2014:869610. DOI: 10.1155/2014/869610.

[67] Gotteland M, Cires MJ, Carvallo C, Vega N, Ramirez MA, Morales P, Rivas P, Astudillo F, Navarrete P, Dubos C, Figueroa A, Troncoso M, Ulloa C, Mizgier ML, Carrasco-Pozo C, Speisky H, Brunser O, Figueroa G. Probiotic screening and safety evaluation of Lactobacillus strains from plants, artisanal goat cheese, human stools, and breast milk. J Med Food. 2014;17(4):487-495. DOI: DOI: 10.1089/jmf.2013.0030.

[68] Dec M, Puchalski A, Urban-Chmiel R, Wernicki A. Screening of Lactobacillus strains of domestic goose origin against bacterial poultry pathogens for use as probiotics. Poult Sci. 2014;93(10):2464-2472. DOI: DOI: 10.3382/ps.2014-04025.

[69] Amer EI, Mossallam SF, Mahrous H. Therapeutic enhancement of newly derived bacteriocins against Giardia lamblia. Exp Parasitol. 2014;146:52-63. DOI: 10.1016/ j.exppara.2014.09.005.

[70] Mirnejad R, Vahdati AR, Rashidiani J, Erfani M, Piranfar V. The antimicrobial effect of Lactobacillus casei culture supernatant against multiple drug resistant clinical isolates of Shigella sonnei and Shigella flexneri in vitro. Iran Red Crescent Med J. 2013;15(2):122-126. DOI: $10.5812 /$ ircmj.7454.

[71] Jena PK, Trivedi D, Thakore K, Chaudhary H, Giri SS, Seshadri S. Isolation and characterization of probiotic properties of Lactobacilli isolated from rat fecal microbiota. Microbiol Immunol. 2013;57(6):407-416. DOI: 10.1111/1348-0421.12054.

[72] Wu CC, Lin CT, Wu CY, Peng WS, Lee MJ, Tsai YC. Inhibitory effect of Lactobacillus salivarius on Streptococcus mutans biofilm formation. Mol Oral Microbiol. 2015;30(1):1626. DOI: $10.1111 /$ omi.12063.

[73] Torres NI, Noll KS, Xu S, Li J, Huang Q, Sinko PJ, Wachsman MB, Chikindas ML. Safety, formulation, and in vitro antiviral activity of the antimicrobial peptide subtilosin against herpes simplex virus type 1. Probiotics Antimicrob Proteins. 2013;5(1):26-35. DOI: 10.1007/s12602-012-9123-x.

[74] Das A, Nakhro K, Chowdhury S, Kamilya D. Effects of potential probiotic Bacillus amyloliquefaciens [corrected] FPTB16 on systemic and cutaneous mucosal immune responses and disease resistance of catla (Catla catla). Fish Shellfish Immunol. 2013;35(5):1547-53. DOI: 10.1016/j.fsi.2013.08.022.

[75] Chew SY, Cheah YK, Seow HF, Sandai D, Than LT. Probiotic Lactobacillus rhamnosus GR-1 and Lactobacillus reuteri RC-14 exhibit strong antifungal effects against vulvovaginal candidiasis-causing Candida glabrata isolates. J Appl Microbiol. 2015;118(5):11801190. DOI: $10.1111 /$ jam.12772. 
[76] Bian X, Evivie SE, Muhammad Z, Luo GW, Liang HZ, Wang NN, Huo GC. In vitro assessment of the antimicrobial potentials of Lactobacillus helveticus strains isolated from traditional cheese in Sinkiang China against food-borne pathogens. Food Funct. 2016;7: 789-797. DOI: 10.1039/C5FO01041A.

[77] Yang JJ, Niu CC, Guo XH. Mixed culture models for predicting intestinal microbial interactions between Escherichia coli and Lactobacillus in the presence of probiotic Bacillus subtilis. Benef Microbes. 2015;6(6):871-877. DOI: 10.3920/BM2015.0033.

[78] Butprom S, Phumkhachorn P, Rattanachaikunsopon P. Effect of Lactobacillus plantarum $\mathrm{C} 014$ on innate immune response and disease resistance against Aeromonas hydrophila in hybrid catfish. ScientificWorldJournal. 2013;2013:392523. DOI: $10.1155 / 2013 / 392523$.

[79] Gonzalez-Gil F, Diaz-Sanchez S, Pendleton S, Andino A, Zhang N, Yard C, Crilly N, Harte F, Hanning I. Yerba mate enhances probiotic bacteria growth in vitro but as a feed additive does not reduce Salmonella Enteritidis colonization in vivo. Poult Sci. 2014;93(2):434-440. DOI: 10.3382/ps.2013-03339.

[80] Muñoz-Quezada S, Bermudez-Brito M, Chenoll E, Genovés S, Gomez-Llorente C, Plaza-Diaz J, Matencio E, Bernal MJ, Romero F, Ramón D, Gil A. Competitive inhibition of three novel bacteria isolated from faeces of breast milk-fed infants against selected enteropathogens. Br J Nutr. 2013;109;(2):S63-S69. DOI: 10.1017/ S0007114512005600.

[81] Likotrafiti E, Tuohy KM, Gibson GR, Rastall RA. Development of antimicrobial synbiotics using potentially-probiotic faecal isolates of Lactobacillus fermentum and Bifidobacterium longum. Anaerobe. 2013;20:5-13. DOI: 10.1016/j.anaerobe.2013.01.002.

[82] Lazarenko L, Babenko L, Shynkarenko Sichel, Pidgorskyi V, Mokrozub V, Voronkova O, Spivak M. Antagonistic action of Lactobacilli and bifidobacteria in relation to Staphylococcus aureus and their influence on the immune response in cases of intravaginal Staphylococcosis in mice. Probiotics Antimicrob Proteins. 2012;4(2):78-89.

[83] Bratz K, Gölz G, Janczyk P, Nöckler K, Alter T. Analysis of in vitro and in vivo effects of probiotics against Campylobacter spp. Berl Munch Tierarztl Wochenschr. 2015;128(34):155-162.

[84] Gupta R, Sarkar S, Srivastava S. In vivo toxicity assessment of antimicrobial peptides (AMPs LR14) derived from Lactobacillus plantarum Strain LR/14 in Drosophila melanogaster. Probiotics Antimicrob Proteins. 2014;6(1):59-67. DOI: 10.1007/s12602-0139154-y.

[85] Mossallam SF, Amer EI, Diab RG. Potentiated anti-microsporidial activity of Lactobacillus acidophilus CH1 bacteriocin using gold nanoparticles. Exp parasitol. 2014;144:1421. 
[86] Morya VK, Choi W, Kim EK. Isolation and characterization of Pseudoalteromonas sp. from fermented Korean food, as an antagonist to Vibrio harveyi. Appl Microbiol Biotechnol. 2014;98(3):1389-1395. DOI: 10.1007/s00253-013-4937-3.

[87] Dore MP, Cuccu M, Pes GM, Manca A, Graham DY. Lactobacillus reuteri in the treatment of Helicobacter pylori infection. Intern Emerg Med. 2014;9:649-654. DOI: 10.1007/ s11739-013-1013-z

[88] Pendharkar S, Brandsborg E, Hammarström L, Marcotte H, Larsson PG. Vaginal colonisation by probiotic lactobacilli and clinical outcome in women conventionally treated for bacterial vaginosis and yeast infection. BMC Infect Dis. 2015;15:255. DOI: 10.1186/s12879-015-0971-3.

[89] Hauser G, Salkic N, Vukelic K, Jajac Knez A, Stimac D. Probiotics for standard triple Helicobacter pylori eradication: a randomized, double-blind, placebo-controlled trial. Medicine (Baltimore). 2015;94(17):e685, DOI: 10.1097/MD.0000000000000685.

[90] Fox MJ, Ahuja KD, Robertson IK, Ball MJ, Eri RD. Can probiotic yogurt prevent diarrhoea in children on antibiotics? A double-blind, randomised, placebo-controlled study. BMJ Open. 2015;5(1):e006474. DOI: 10.1136/bmjopen-2014-006474.

[91] Srinarong C, Siramolpiwat S, Wongcha-um A, Mahachai V, Vilaichone RK. Improved eradication rate of standard triple therapy by adding bismuth and probiotic supplement for Helicobacter pylori treatment in Thailand. Asian Pac J Cancer Prev. 2014;15(22): 9909-9913.

[92] Dietrich CG, Kottmann T, Alavi M. Commercially available probiotic drinks containing Lactobacillus casei DN-114001 reduce antibiotic-associated diarrhea. World J Gastroenterol. 2014;20(42):15837-15844. DOI: 10.3748/wjg.v20.i42.15837.

[93] Bodean O, Munteanu O, Cirstoiu C, Secara D, Cirstoiu M. Probiotics-a helpful additional therapy for bacterial vaginosis. J Med Life. 2013;6(4):434-436.

[94] Papadimitriou K, Zoumpopoulou G, Foligné B, Alexandraki V, Kazou M, Pot B, Tsakalidou E. Discovering probiotic microorganisms: in vitro, in vivo, genetic and omics approaches. Front Microbiol. 2015;6:58. DOI: 10.3389/fmicb.2015.00058.

[95] Basyigit Kilic G, Kuleasan H, Sömer VF, Akpinar D. Determining potential probiotic properties of human originated Lactobacillus plantarum Strains. Biotechnol Bioprocess Eng. 2013;18:479-485. DOI: 10.1007/s12257-012-0785-8.

[96] Jamalifar H, Rahimi HR, Samadi N, Shahverdi AR, Sharifian Z, Hosseini F, Eslahi H, Fazeli MR. Antimicrobial activity of different Lactobacillus species against multi-drug resistant clinical isolates of Pseudomonas aeruginosa. Iran J Microbiol. 2011;3(1):21-25.

[97] Carasi P, Díaz M, Racedo SM, De Antoni G, Urdaci MC, Serradell Mde L. Safety characterization and antimicrobial properties of kefir-isolated Lactobacillus kefiri. Biomed Res Int. 2014;2014:208974. DOI: 10.1155/2014/208974. 
[98] Zavišić G, Ristić S, Petrièević S, Novaković Jovanović J, Janać Petković B, Strahinić I, Piperski V. Characterisation and preliminary lipid-lowering evaluation of Lactobacillus isolated from a traditional Serbian dairy product. Benef Microbes. 2015;6(1):119128. DOI: 10.3920/BM2014.0018.

[99] Goyal N, Dixit K, Gandhi D. Antimicrobial activity of probiotic Lactobacillus strains towards Salmonella enterica ser enteritidis in whey. Internet J Microbiol. 2007;5(1):6.

[100] Shandilya UK, Sharma A, Kapila R, Kansal VK. Probiotic Dahi containing Lactobacillus acidophilus and Bifidobacterium bifidum modulates immunoglobulin levels and cytokines expression in whey proteins sensitized mice. J Sci Food Agric. 2015. DOI: 10.1002/jsfa.7497.

[101] Kaushal D, Kansal VK. Dahi containing Lactobacillus acidophilus and Bifidobacterium bifidum improves phagocytic potential of macrophages in aged mice. J Food Sci Technol. 2014;51(6):1147-1153. DOI 10.1007/s13197-012-0637-8.

[102] Tan Q1, Xu H, Aguilar ZP, Peng S, Dong S, Wang B, Li P, Chen T, Xu F, Wei H. Safety assessment and probiotic evaluation of Enterococcus faecium YF5 isolated from sourdough. J Food Sci. 2013;78(4):M587-M593. DOI: 10.1111/1750-3841.12079.

[103] Argyri AA, Zoumpopoulou G, Karatzas KA, Tsakalidou E, Nychas GJ, Panagou EZ, Tassou CC. Selection of potential probiotic lactic acid bacteria from fermented olives by in vitro tests. Food Microbiol. 2013;33(2):282-291. DOI: 10.1016/j.fm.2012.10.005.

[104] Isa K, Oka K, Beauchamp N, Sato M, Wada K, Ohtani K, Nakanishi S, McCartney E, Tanaka M, Shimizu T, Kamiya S, Kruger C, Takahashi M. Safety assessment of the Clostridium butyricum MIYAIRI $588^{\circledR}$ probiotic strain including evaluation of antimicrobial sensitivity and presence of Clostridium toxin genes in vitro and teratogenicity in vivo. Hum Exp Toxicol. 2015. DOI: 10.1177/0960327115607372.

[105] Eberhart LJ, Ochoa JN, Besser TE, Call DR. Microcin MccPDI reduces the prevalence of susceptible Escherichia coli in neonatal calves. J Appl Microbiol. 2014;117(2):340-346. DOI: 10.1111/jam.12535.

[106] Iordache F, Iordache C, Chifiriuc MC, Bleotu C, Smarandache D, Sasarman E, Laza V, Bucu M, Dracea D, Larion C, Cota A, Lixandru M. Antimicrobial and immunomodulatory activity of some probiotic fractions with potential clinical application. Arch Zootech. 2008;11(3): 41-51.

[107] Beganović J1, Kos B, Leboš Pavunc A, Uroić K, Džidara P, Šušković J. Proteolytic activity of probiotic strain Lactobacillus helveticus M92. Anaerobe. 2013;20:58-64. DOI: 10.1016/j.anaerobe.2013.02.004.

[108] Soleimani NA, Kermanshahi RK, Yakchali B, Sattari TN. Antagonistic activity of probiotic lactobacilli against Staphylococcus aureus isolated from bovine mastitis. Afr J Microbiol Res. 2010;4(20):2169-2173.

[109] Buffie CG, Bucci V, Stein RR, McKenney PT, Ling L, Gobourne A, No D, Liu H, Kinnebrew M, Viale A, Littmann E, van den Brink MR, Jenq RR, Taur Y, Sander C, 
Cross JR, Toussaint NC, Xavier JB, Pamer EG. Precision microbiome reconstitution restores bile acid mediated resistance to Clostridium difficile. Nature. 2015;517(7533): 205-208. DOI: 10.1038/nature13828.

[110] Atkinson S, Williams PJ. Quorum sensing and social networking in the microbial world. R Soc Interface. 2009;6(40):959-978. 
